\title{
Dietary Practices and Anthropometric Profile of Professional Male Surfers
}

\author{
Sandra Maria Lima Ribeiro ${ }^{1}$, Angélica Marques Pina Freitas ${ }^{1}$, Benedito Pereira ${ }^{2}$, Ricardo Vilalva ${ }^{3}$, Kleverton \\ Krinski ${ }^{4}$ and Tácito Pessoa Souza-Junior ${ }^{4}$ \\ 1. School of Arts, Sciences and Humanities, University of São Paulo, São Paulo, SP 04101-000, Brazil \\ 2. School of Physical Education and Sport, University of São Paulo, São Paulo, SP 05508-030, Brazil \\ 3. Department of Physiotherapy, University of Ribeirão Preto, Campus Guarujá, Guarujá, SP 11440-003, Brazil \\ 4. Department of Physical Education, Federal University of Parana, Curitiba, PR 80210-132, Brazil
}

\begin{abstract}
Aims: To identify dietary practices together with anthropometric variables of a group of professional surfers. Subjects: Participants of a National Surf Championship in Brazil. Evaluations: (1) Anthropometric measures, indexes and calculations (body mass, height, arm span, body circumferences and nine skinfold thicknesses, arm spam/height ratio, waist-to-hip-ratio, conicity index and $\%$ body fat); (2) One $24 \mathrm{~h}$ food-recall, describing all the food and drinks consumed at the previous day, and analyzed for energy, macro-nutrients, some micro-nutrients and food groups. The values were compared with some references and position statements and with the Brazilian Food Guide; (3) The basal and daily energy expenditure was estimated from specific equations; the energy intake was estimated from the information on diet and the energy balance was estimated from the difference between these values. Main results: The intake of carbohydrate is below the position statements $(2.5-9.7 \mathrm{~g} / \mathrm{kg}$ and $6-10 \mathrm{~g} / \mathrm{kg}$ body weight, respectively). Possibly the intake of supplements such as maltodextrin fulfilled the requirements (30.3\% of the athletes referred the intake of this supplement); The intake of BCAA (Branched-Chain Amino Acids) showed to be high (24.2\% of the athletes); The low intake of vegetables possibly contributes to the low intake of micronutrients (0.0-6.0 servings, against the recommendation of 4-5 servings); The high intake of fried food (added lipid = 0.0-5.9 servings, against the recommendation of 1.0-2.0 servings) overlapped healthy habits such as beans and nuts consumption (0.0-13.6 servings against the recommendation of 1.0 serving); The percentage of body fat seems to be similar to swimmers (around 12\% of body weight). As a conclusion, the dietary practices of surfers in the day prior a competition need to be improved, especially with respect to carbohydrates and lipids. The balance between energy intake and energy expenditure needs to be investigated more deeply. Studies investigating the role of certain amino acids supplement, such as BCAA, in surf practice could allow a better interpretation of this practice.
\end{abstract}

Key words: Surf, nutritional status, anthropometry, diet analysis.

\section{Introduction}

It is difficult to find official documents describing the exact origin of surf. This sport modality is many centuries old, maybe millenniums. Historically, it was considered the pleasure of gliding over the waves by Hawaiian kings [1]. Others unofficial registers point old Peru civilization as the first to adopt sport practices similar to surf. In addition, a Hawaiian world Champion swimmer called Duke Paoa Kahanamoku is

Corresponding author: Sandra Maria Lima Ribeiro, Ph.D., associate professor, research fields: nutrition and aging. E-mail: smlribeiro@usp.br. said to be the first to spread the surf as a sport modality. The professional practice of surf is pointed to start on 70 and 80 decades. Nowadays, there are a number of countries where this practice is common and admired, such as USA and Australia. Brazil has improved this practice throughout the years [1,2].

Until nowadays, despite the popularity of competitive surf, little research has investigated physiologic and metabolic profile of surf athletes. Recently, two elegant studies [3, 4] described some features of this sport. The authors showed that from the TT (total time) spent on a surf competition, the greatest 
amount of time is paddling $(54.0 \pm 6.3 \%$ of TT); remaining stationary represents $28.0 \pm 6.9 \%$, wave riding $8.0 \pm 2.0 \%$ and paddling for a wave $4.0 \pm 1.5 \%$. The mean heartbeat was found to be $139 \pm 11$ beats/min (64\% HRmax). Competitive surfing therefore is composed by intermittent high intensity bouts of paddling intercalated with short recovery periods and repeated bouts of low intensity paddling.

All these features highlight the recruitment of all the body's energy stores. To allow the mobilization of energy substrates, appropriate body composition conditions are necessary. There are a number of studies pointing the specificity of anthropometric profile in different sports modalities, that is, there is an "ideal" morphological profile to each sport, since anthropometric evaluation can be a good strategy to monitor and control the physical training [5, 6]. For instance, subcutaneous fat, besides its importance as an energy substrate to aerobic metabolism in surf, may serve as thermal isolation to face variations in temperature of water environment. There are some studies investigating the importance of body composition of swimmers [7, 8], however, it is not known if surfers have similar needs.

Additionally, it is well known the role of nutrition to performance and to health $[9,10]$ in different sports modalities. Looking at the physiologic and metabolic features of surf, it can be concluded that feeding practices have to optimize aerobic and anaerobic systems of energy transformation. In this way, carbohydrates from diet are important source of energy to anaerobic peaks and to blood glucose maintenance to medium and long term demands [11]. Protein, besides its important role in fat free mass, can serve as energy alternative to muscle, mainly from specific amino acids such as the branched chain amino acidsBCAA [12, 13]. In addition, it is important to have in mind that metabolic utilization of macro-nutrients is dependent on the appropriate supply of vitamins and minerals, since they are co-factors of a number of enzymatic processes and have an important role as antioxidants [11]. Still, it is necessary to bear in mind the different moments of training and competition. For example, pre-exercise diet has to give priority to low and medium glycemic index carbohydrates, together with easily digestive fats and proteins [11].

Therefore, the investigation of nutritional status of athletes, considering together anthropometric and diet information, is fundamental to achieve the best conditions of health and performance in different sports. Considering the lack of information regarding nutritional status of surfers, the present study has the aim to identify pre-competition dietary practices together with anthropometric variables of a group of these athletes.

\section{Methods}

\subsection{Subjects}

The voluntaries of the study were recruited at a National Surf Championship in Brazil (Super Surf, 2008), where only the 48 previously qualified elite surfers are allowed to take part on. After explanation about the aims and the importance of the study, the ones who accepted to take part of the study signed in a written informed consent. The study was approved by the local ethic committee.

\subsection{Data Collection}

All the evaluations were performed at a specific place designed to these analyses, at the competition site, arranged by Brazilian Association of Professional Surf. The voluntaries were evaluated in the day of the competition, in the morning, and the subjects were advised not to eat or drink before the analysis. After completion of the evaluations, a breakfast was offered to all the participants.

\subsection{Anthropometry}

The anthropometric variables measured were: body mass, with scale with maximum weight of $150 \mathrm{~kg}$ (Filizola ${ }^{\circledR}$ scale), height (Sanny® stadiometer), arm span, body circumferences (chest, waist, abdominal, 
hip, thigh, leg, arm, forearm, wrist), with an inelastic tape. The following skinfold thicknesses were measured: SE (subscapular), MA (madiaxillary), $\mathrm{CH}$ (chest), AB (abdominal), SI (suprailiac), TH (thigh), MC (medial calf), TR (triceps), BI (biceps) (Lange ${ }^{\circledR}$ caliper). All the procedures to anthropometric measures were based on Lohman, Roche \& Martorell [14]. From the anthropometric measures, the following indexes, ratios and calculations were made: body mass index $\left(\mathrm{BMI}=\mathrm{BW} / \mathrm{Ht}^{2}\right)$, arm spam/height ratio, waist-to-hip-ratio, and conicity index $(\mathrm{CI}=$ [Waist circumference (m)/0.109 $\times \square$ Bodymass index)] [15]. The nine skinfold thicknesses measured were summed up and some of them were used to estimate the body density and the $\%$ of body fat, according to the following formulas:

Body density $=1.10938-0.0008267 \times\left(\sum 3 \mathrm{ST}\right)+$ $0.0000016 \times\left(\sum 3 \mathrm{ST}\right)\left(\sum 3 \mathrm{ST}\right)-0.0002574 \times($ Height $)$, where $\sum 3 \mathrm{ST}=\mathrm{CH}+\mathrm{AB}+\mathrm{TH}[16]$, Body fat $=$ [(4.95/Body density $)-4.5] \times 100$ [17].

\subsection{Diet Analysis}

After the anthropometric measurements, the subjects answered a $24 \mathrm{~h}$ food-recall. From mnemonics strategies, they described all the food and drinks consumed at the previous day. The DEI (intake of energy), macronutrients (carbohydrates, lipids and proteins) and some micro-nutrients were calculated with specific software (VirtualNutri (®)). The values obtained were compared with some references and position statements $[11,18,19]$. In addition, the $24 \mathrm{~h}$ food-recall was analyzed for food groups and their serving size, based on the Brazilian Food Guide [20].

\subsection{Energy Balance}

From anthropometric measures, the BEE (basal energy expenditure, in kilocalories/day) was predicted, utilizing the FAO/WHO/UNU (19) predictive equations, as follow:

$\operatorname{BEE}(\mathrm{Kcal} /$ day $)=15.4 \times$ body mass $+27 \times$ Height + 717 (Age 18 to 30 year old); BEE (Kcal/day) $=11.3 \times$ body mass $+16 \times$ Height +901 (Age above 30 years old).

To estimate the daily energy expenditure (DEE, in kilocalories/day), the factor of 2.1 was multiplied by the BEE (which corresponds to heavy intensity daily activity). Indeed, the EB (energy balance) was estimated subtracting the daily energy expenditure from DEI (daily energy intake, in kilocalories, from the $24 \mathrm{~h}$ food recall), as following:

$$
\mathrm{EB}=\mathrm{DEI}-\mathrm{DEE}
$$

The data are presented as mean, standard deviation and range of the values. No other statistical analysis beyond descriptive was used. To descriptive statistics and to the graphs plotting, it was used the software

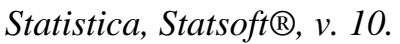

\section{Results}

The number of volunteers evaluated for anthropometry and diet recall was 33, all of them males. The participants' age was $27.3 \pm 5.2$ (range 19.0-42.0) years old.

Table 1 depicts the anthropometric variables analyzed. None of the athletes presented any indicative risk of diseases associated to body fat. The mean percentage of body fat was around $12 \%$, and this information is detailed at Fig. 1.

Table 2 presents the quantitative analysis of nutrients intake from $24 \mathrm{~h}$ food recall. Comparing these values with the references, the athletes ingested low amount of carbohydrate and folic acid in the day before the competition. Table 3 shows the intake of nutrition supplements, where it can be noticed that maltodextrin and BCAA were the most consumed ones. Fig. 2 describes the percentage distribution between macro-nutrients and the distribution between the types of fat consumed. Saturated fat was the most consumed type of fat.

Table 4 describes the ingestion of the different food groups by the athletes. There was a great variability of the data, and it is noticeable the low intake of fruits, vegetables and at the same time the high intake of 
Table 1 Anthropometric measures, indexes and calculations (mean \pm SD and range).

\begin{tabular}{|c|c|c|}
\hline Anthropometric Variables & Mean \pm SD & Range \\
\hline \multicolumn{3}{|l|}{ Measures } \\
\hline Body mass (kg) & $73.7 \pm 7.0$ & $62.9-92.3$ \\
\hline Height (cm) & $173.1 \pm 5.4$ & $164.0-187.0$ \\
\hline Arm Spam (cm) & $179.7 \pm 7.5$ & $166.0-196.0$ \\
\hline Chest (cm) & $99.7 \pm 4.3$ & $86.0-109.0$ \\
\hline Waist (cm) & $79.1 \pm 3.2$ & $72.0-86.0$ \\
\hline Abdominal $(\mathrm{cm})$ & $81.6 \pm 4.1$ & $73.2-91.0$ \\
\hline Hip $(\mathrm{cm})$ & $94.2 \pm 4.2$ & $88.5-107.0$ \\
\hline Thigh $(\mathrm{cm})$ & $54.4 \pm 2.8$ & $48.0-63.5$ \\
\hline $\operatorname{Leg}(\mathrm{cm})$ & $34.7 \pm 2.6$ & $27.0-39.5$ \\
\hline $\operatorname{Arm}(\mathrm{cm})$ & $32.3 \pm 1.59$ & $30.0-37.0$ \\
\hline Forearm $(\mathrm{cm})$ & $26.5 \pm 2.1$ & $17.0-30.5$ \\
\hline Wrist $(\mathrm{cm})$ & $16.9 \pm 2.7$ & $17.0-30.5$ \\
\hline \multicolumn{3}{|c|}{ Ratios, indexes and calculations } \\
\hline Arm Spam/height ratio & $1.04 \pm 0.03$ & $0.99-1.08$ \\
\hline Body mass index $\left(\mathrm{kg} / \mathrm{m}^{2}\right)$ & $24.6 \pm 1.6$ & $21.1-28.8$ \\
\hline Waist-hip-ratio & $0.84 \pm 0.03$ & $0.76-0.91$ \\
\hline Conicity index ${ }^{1}$ & $14.6 \pm 0.5$ & $13.6-15.6$ \\
\hline Sum 9 skin folder $(\mathrm{mm})^{2}$ & $94.4 \pm 25.1$ & $57.0-163.0$ \\
\hline$\%$ body fat ${ }^{3}$ & $12.2 \pm 3.6$ & $5.5-20.8$ \\
\hline
\end{tabular}

1: According toValdez (1991); 2: sum of the skinfold thicknesses (subscapular, madiaxillary, chest, abdominal, suprailiac, thigh, medial calf, triceps, biceps); 3: According to Jackson \& Pollock predictive equation (1978).

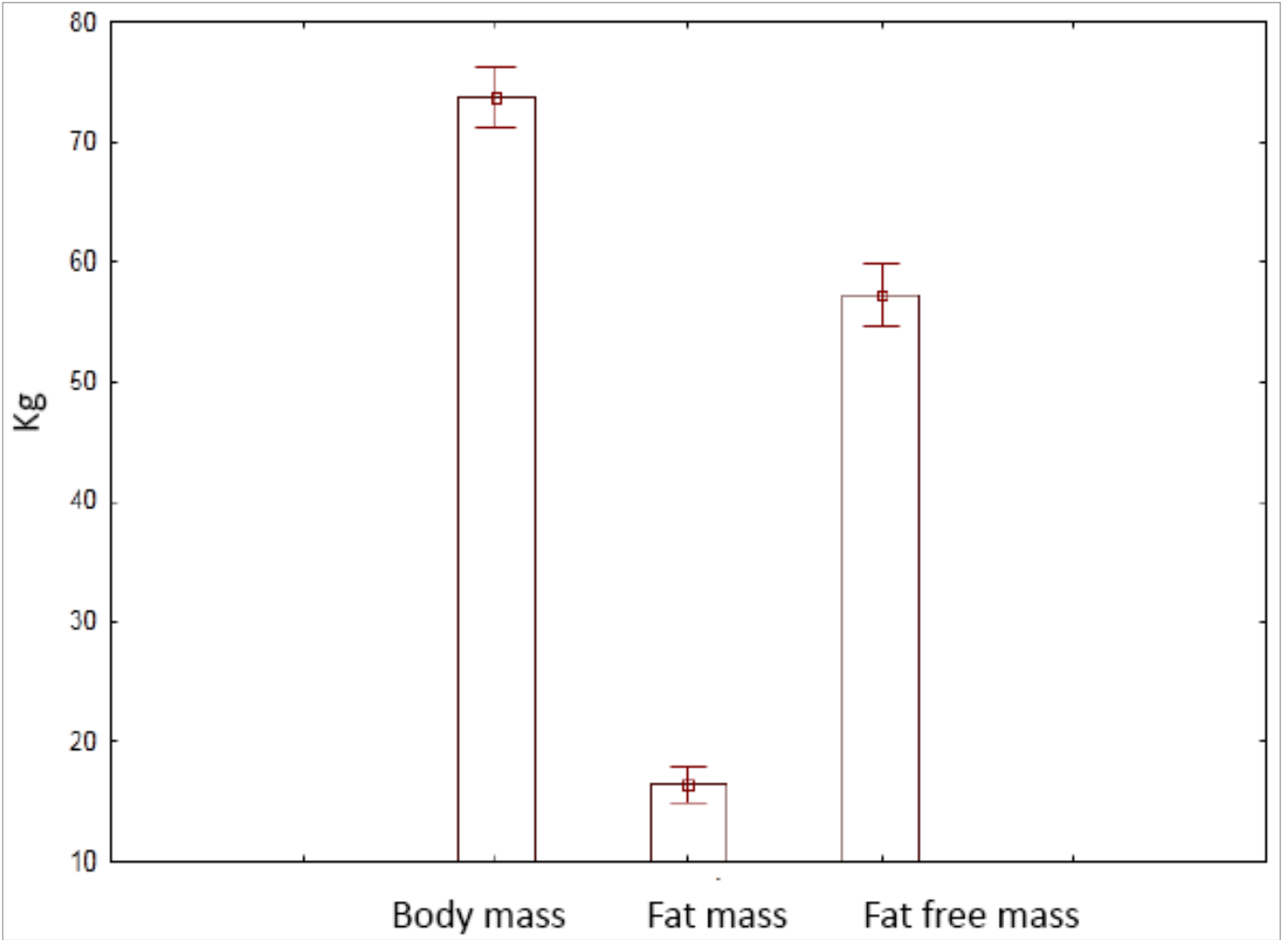

Fig. 1 Body composition of the athletes, according to anthropometric estimative of fat mass and fat-free mass. 
Table 2 Nutrient intake by the athletes, according to $24 \mathrm{~h}$ food recall (mean \pm SD and range).

\begin{tabular}{|c|c|c|c|}
\hline Nutrient & Mean \pm SD & Range & Proposed value's range ${ }^{1,2,3}$ \\
\hline Energy & $2982 \pm 971$ & $2982-5170$ & $1468-5170^{1}$ \\
\hline Carbohydrate (g) & $391.5 \pm 147.2$ & 181.6-770.1 & - \\
\hline $\mathrm{g} / \mathrm{Kg}$ body weight & $5.3 \pm 1.9$ & $2.5-9.7$ & $6-10^{3}$ \\
\hline Fat $(\mathrm{g})$ & $106.5 \pm 40.4$ & $30.3-171.4$ & - \\
\hline Protein $(\mathrm{g})$ & $131.9 \pm 48.7$ & $55.0-249.6$ & - \\
\hline $\mathrm{g} / \mathrm{kg} \mathrm{BW}$ & $1.8 \pm 0.6$ & $0.8-3.5$ & $1.2-1.7^{3}$ \\
\hline Total fiber & $27.2 \pm 15.1$ & $6.7-80.4$ & $38^{2}$ \\
\hline Vit C (mg) & $214.9 \pm 173.9$ & $12.0-670.3$ & $90.0^{2}$ \\
\hline Vit D (ug) & $5.5 \pm 3.2$ & $0.9-11.7$ & $5.0^{2}$ \\
\hline Vit E (mg) & $25.7 \pm 16.5$ & $5.9-73.5$ & $15.0^{2}$ \\
\hline Tiamin (Vit B1) (mg) & $2.8 \pm 1.8$ & $0.8-10.5$ & $1.2^{2}$ \\
\hline Riboflavin (Vit B2) (mg) & $2.5 \pm 1.2$ & $1.0-6.3$ & $1.3^{2}$ \\
\hline Piridoxin (Vit B6) (mg) & $3.2 \pm 1.3$ & $0.9-5.9$ & $1.3^{2}$ \\
\hline Cianocobalamin (Vit B12) (ug) & $5.3 \pm 2.5$ & $1.4-10.0$ & $2.4^{2}$ \\
\hline Niacin (Vit. B3) (Niacin Eq) & $34.3 \pm 15.2$ & $12.6-72.3$ & $16.0^{2}$ \\
\hline Folate (ug folate Eq) & $300.5 \pm 153.2$ & $12.6-72.3$ & $400.0^{2}$ \\
\hline Panthotenic Acid (mg) & $5.6 \pm 1.6$ & $2.1-8.8$ & $5.0^{2}$ \\
\hline Iron (mg) & $21.8 \pm 10.0$ & $9.4-54.1$ & $6.0^{2}$ \\
\hline Zinc (mg) & $13.5 \pm 7.6$ & $4.0-39.3$ & $9.4^{2}$ \\
\hline Selenium (ug) & $140.8 \pm 62.2$ & $22.8-327.6$ & $45.0^{2}$ \\
\hline
\end{tabular}

1: Predictive values range, from WHO equations (FAO/WHO/UNU, 1985 ); 2: Dietary reference intake (Ottem et al, 2006 ); 3 : ACSM/ADA/DC position statement (ACSM, 2009).

Table 3 Frequency of Nutritional Supplements consumption by the athletes.

\begin{tabular}{ll}
\hline Type of Supplement & Number of athletes (\% of the total of 33 athletes) who referred the consumption \\
\hline Maltodextrin & $10(30.3)$ \\
Whey protein & $9(27.3)$ \\
Branched Chain Amino acids (BCAA) & $8(24.2)$ \\
Multivitamins (Centrum, ABC plus) & $5(15.2)$ \\
Yeast & $2(6.1)$ \\
Meal substitutes (Myoplex, Diet shake) & $2(6.1)$ \\
Vitamin C & $1(3.0)$ \\
Creatine & $1(3.0)$ \\
Fish Oil & $1(3.0)$ \\
\hline
\end{tabular}

meats, and added sugar and fat. Detailing the intra-group intake (not shown in the Table), the bread was the most consumed food from the group of cereals. Regarding to fruits, banana was the most consumed, together with fruits juices. From the vegetables, the only ones referred by the athletes were lettuce, tomato and carrots. The high consumption of nuts and peanuts enhanced the intake of beans by some athletes. The intake of fat is mainly due to a high amount of fried food referred by the athletes. Fruits juices are also added with a high amount of sugar by the group. Soft drinks and chocolate are also responsible by the high consumption of sugar group.

Fig. 3 shows the energy balance by the group. Even with high variability, we can state that the majority of the athletes presented a negative energy balance.

\section{Discussion}

In order to contribute with information about nutritional status of professional surfers, the present study described some anthropometric variables and some feeding practices of these athletes. The body fat 


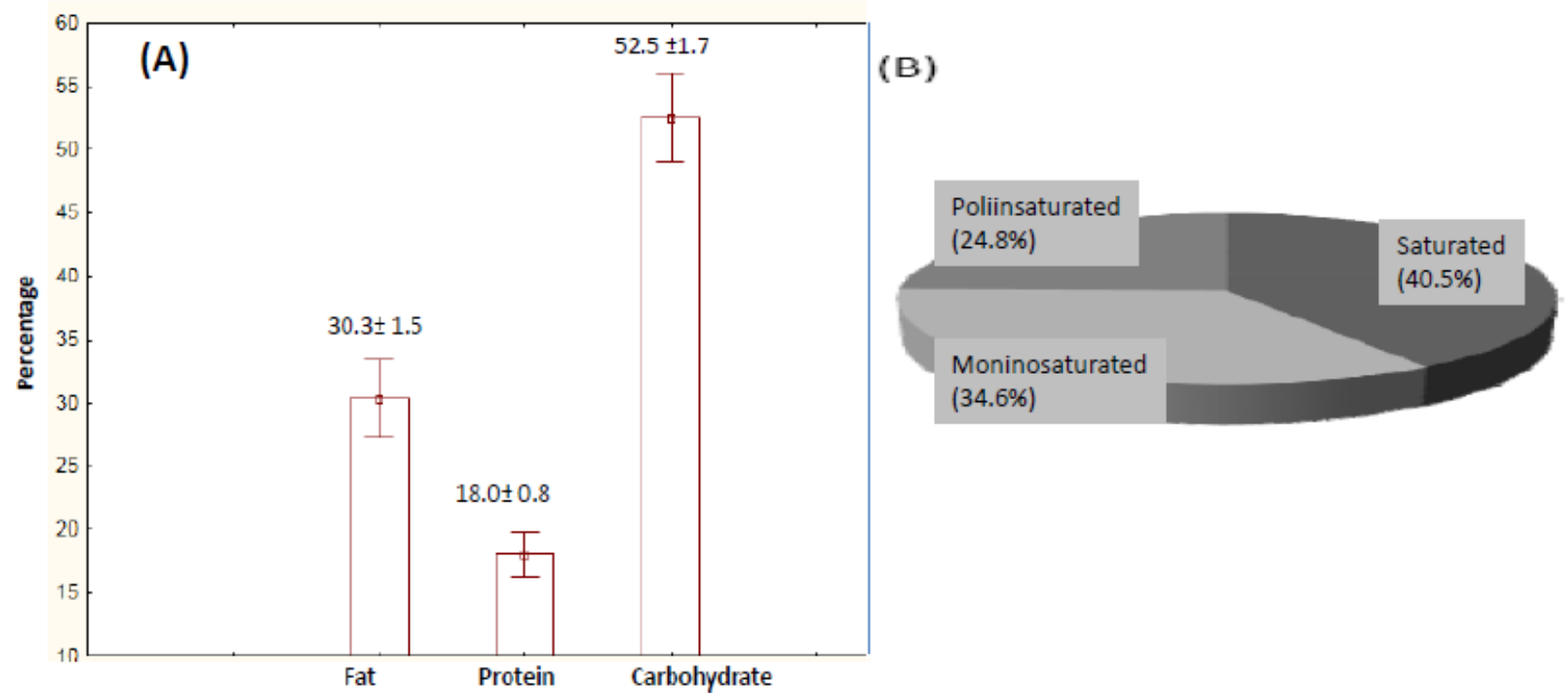

Fig. 2 Percentage of energy intake related to macronutrients (A) and percentage distribution of the different types of fat (Sat (saturated), Mono (monounsaturated) and Poli (polyunsaturated)) (B).

Table 4 Semi-quantitative description of food group consumed by the athletes.

\begin{tabular}{lll}
\hline Food Group & Range of referred consumption (mean \pm SD) & ${ }^{1}$ \\
Cereals & $0.8-16.1(6.4 \pm 4.0)$ & $5-9$ \\
Fruits & $0.0-13.9(4.4 \pm 3.6)$ & $3-5$ \\
Vegetables & $0.0-6.0(1.7 \pm 1.7)$ & $4-5$ \\
Meat, Poultry, Fish, Eggs & $0.7-7.7(3.2 \pm 1.8)$ & $1-2$ \\
Dairy & $0.0-10.0(3.0 \pm 2.2)$ & 3 \\
Beans and nuts & $0.0-13.6(2.3 \pm 2.8)$ & 1 \\
Added fat & $0.0-5.9(1.3 \pm 1.7)$ & $1-2$ \\
Added sugar & $0.1-7.6(3.0 \pm 2.0)$ & $1-2$ \\
\hline
\end{tabular}

1: Acording to 24h food recall; 2: Brazilian food guide (Health Ministry, 2008).

percentage of $12 \%$ is above other sports modalities [21, 22], but similar to swimmers. Fleck et al [23] pointed that athletes involved in a sport where their body weight is supported, such as canoe and swimming, tended to have higher $\%$ fat values $(13.0 \pm 2.5 \%$ and $12.4 \pm 3.7 \%$, respectively).

We observed the results of dietary energy intake and energy expenditure in form of energy balance. From these results, the athletes presented a deficit of energy intake, which is not coherent with the body composition results or even with the fact that they are professional athletes. Looking for an explanation to that, it is important to remember the statements of FAO/WHO/ONU [19]; they suggest that if the individuals are in a healthy and appropriate body composition and good level of physical activity, the possibility of under consumption is certainly unlikely. Therefore, other possibilities to these results have to be thought. First, the deficit of energy intake identified in the diet could be attenuated by the consumption of supplement (mainly maltodextrin, BCAA or whey protein), which were not included in the energy intake calculation in our study. The second possibility is misreporting of the energy intake. Scagliusi \& Lancha Junior [24] found misreporting in different groups, and justified this practice by factors such as perceptive, emotional and cognitive components. Many studies point athlete of different modalities [25-28], as well as the general population [29], use to misreport the energy intake in order to describe practices similar to their 


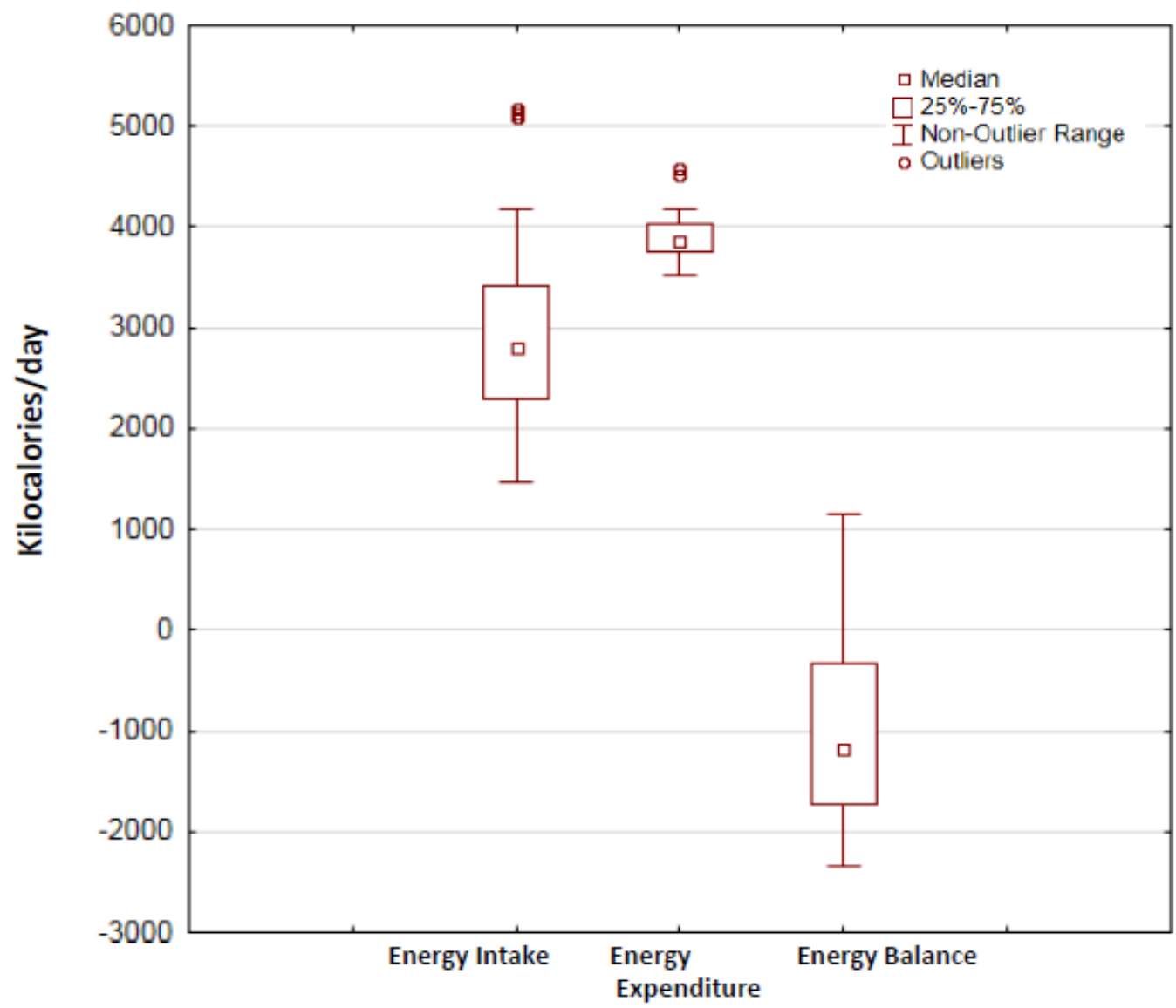

Fig. 3 Energy balance, energy intake and energy expenditure by the athletes, according to 24h food recall and WHO (1985).

pairs. For instance, obese people tend to report energy intake similar to non-obese people [30], and athletes tend to report values similar to non-athletes [31].

Regarding the intake of specific nutrients, surfers of the present study ingested low amount of carbohydrates, compared to the position statement of ACSM/ADA/DC [11]. Carbohydrates are fundamental as energy fuel in intermittent activities (one feature of surf), mainly due to mobilization of muscle glycogen [32-34]. During competitive periods [11] it has been suggested an enhancement of the carbohydrate intake to around $10 \mathrm{~g} / \mathrm{kg} / \mathrm{day}$, and the mean intake referred by the surfers of the present study was 5.3\%. Some of the athletes (eight of them) referred the consumption of maltodextrin (a carbohydrate supplement), which certainly contributed to improved the carbohydrate intake.

The intake of protein showed to be appropriate by the athletes of the present study (mean of $1.8 \mathrm{~g} / \mathrm{kg} /$ day). The ACSM/ADA/DC position state [11] suggests, for endurance activities, 1.2 to $1.4 \mathrm{~g} / \mathrm{kg} / \mathrm{day}$, and to resistance exercises, 1.6 to $1.7 \mathrm{~g} / \mathrm{kg} / \mathrm{day}$. In turn, the International Society of Sports Nutrition [12] position state suggests intervals from 1.4 to $2.0 \mathrm{~g} / \mathrm{kg} /$ day. Protein intake is essential to contribute with aspects associated to immune system, besides the integrity of tissues [35]. Alongside the intake of proteins from diet, eight of the athletes referred the daily intake of BCAA. The collaboration of these specific amino acids to energy metabolism is a controversial issue [36]. Although some authors describe the role of amino acids in the energy transformation to intermittent activities to be irrelevant, others point different results. Tang [13] evaluated swimming performance after a period of BCAA administration. They showed that swimming induced muscle proteolysis was prevented by this type 
of supplementation, because of the ammonia provided by the oxidation of supplemented BCAAs. Therefore, together with the adequate ingestion of proteins by these athletes, the high intake of BCAA deserves more investigations related the possible benefits.

The lipids consumption by the surfers, regardless to be adequate as percentage of energy intake, showed higher proportion of saturated fatty acids, to the detriment of mainly monounsaturated ones. Polyunsaturated and monounsaturated fatty acids, besides its participation in immune function, are responsible for membranes integrity, especially in the nervous system cells [37, 38]. The enhancement of reactive species and trauma during high intensity exercise contribute to an inflammatory state, and some studies point the intake of EPA (eicosapentaenoic acid) and DHA (docosahexaenoic acid), both polyunsaturated fatty acids, to have important benefits in these moments [38].

Summarizing, the main information from the present study were: (1) The intake of carbohydrate possibly is below the suggested, at least considering the day before competition. However, possibly the intake of supplement of maltodextrin completed the carbohydrate requirements; (2) Despite controversies, the intake of BCAA by surfers showed to be high, and more studies are necessary to understand the role of these amino acids in surf; (3) The low intake of vegetables possibly contributes to the low intake of folic acid showed by the athletes; (4) The high intake of fried food overlap a healthy habit of nuts consumption by some of the athletes; (5) The percentage of body fat seems to be similar to swimmers, around $12 \%$ of body weight.

It is important, at this time, to mention the limitations of the present study. The analysis of food intake by self-reports is subject to errors due to food composition tables or even due to the description of food recipes. However, even when energy balance is determined by more sophisticated techniques, the under-reporting is detected by most of the studies [26,
27]. The energy expenditure was estimated from predictive formulas, and these equations were not developed to athletes. Certainly more detailed studies, using more sophisticated techniques such as double labeled water, could clarify our results. The same can be said regarded to methods of body composition, to better describes the amount and distribution of fat mass and fat free mass.

As a conclusion, the dietary practices of surfers in the day prior a competition need to be improved, especially with respect to carbohydrates and lipids. The balance between energy intake and energy expenditure needs to be investigated more deeply. Studies investigating the role of certain amino acids supplement, such as BCAA, in surf practice could allow a better interpretation of this practice.

\section{Practical Applications}

This study certainly will contribute to the understanding of body composition and feeding practices of surfing. Our findings can provide relevant information for future studies seeking the best performance and health of professional surfers. For instance, food and energy intake shown by the athletes are of particular interest to the athletes, coaches and nutritionists, especially thinking about the food plan to these sport modality. The appropriate dietary plan is fundamental to the best performance and health status.

\section{References}

[1] Kampion, D., and Brown, B. 1997. Stoked: A History of Surf Culture. Los Angeles: General Publishing Group Inc.

[2] Warshaw, M. 2010. The History of Surfing. San Francisco: Chronicle Books.

[3] Farley, O. R., Harris, N. K., and Kilding, A. E. 2012. "Anaerobic and Aerobic Fitness Profiling of Competitive Surfers." Journal of Strength \& Conditioning Research 26 (8): 2243-8.

[4] Farley, O. R., Harris, N. K., and Kilding, A. E. 2012. "Physiological Demands of Competitive Surfing." Journal of Strength \& Conditioning Research 26 (7): 1887-96.

[5] Barr, S. I., McCarger, L. J., and Crawford, S. M. 1994. "Practical Use of Body Composition Analysis in Sport." Sports Medicine 17 (5): 277-82. 
[6] Ramana, Y. V., Surya, M. V. L. K., Sudhakar, S. R., and Balakrishna, N. 2004. "Effect of Changes in Body Composition Profile on VO2max and Maximal Work Performance in Athletes." Journal of Exercise Physiology Online 7: 34-9.

[7] Cordain, L. and Kopriva, R. 1991. "Wetsuits, Body Density and Swimming Performance." British Journal of Sports Medicine 25 (1): 31-3.

[8] Keatinge, W. R., Khartchenko, M., Lando, N., and Lioutov, V. 2001. "Hypothermia during Sports Swimming in Water Below $11^{\circ} \mathrm{C} . "$ British Journal of Sports Medicine 35: 352-3.

[9] Probart, C. K., Bird, P. J., and Parker, K. A. 1993 "Diet and Athletic Performance." The Medical Clinics of North America 4: 757-2.

[10] Spriet, L. L., and Peters, S. J. 1998. "Influence of Diet on the Metabolic Responses to Exercise." Proceedings of the Nutrition Society 57 (1): 25-33.

[11] Rodriguez, N. R., DiMarco, N. M., and Langley, S. 2009. "American College of Sports Medicine position stand. Nutrition and athletic performance." Medicine and Science and Sports Exercise 41 (3): 709-31.

[12] Campbell, B., Kreider, R. B., Ziegenfuss, T., La Bounty, P., Roberts, M., Burke, D., Landis, J., Lopez, H. and Antonio, J. 2007. "International Society of Sports Nutrition Position Stand: Protein and Exercise." Journal of International Society of Sports Nutrition 4 (8): 1-13.

[13] Tang F. 2006. "Influence of Branched-Chain Amino Acid Supplementation on Urinary Protein Metabolite Concentrations after Swimming." Journal of the American College of Nutrition 25 (3): 188-94.

[14] Lohman, T. G., Roche, A. F., and Martorell, R. 1991. Anthropometric Standardization Reference Manual. Champaign: Human Kinetic Books.

[15] Valdez, R. 1991. "A Simple Model-Based Index of Abdominal Adiposity." Journal of Clinical Epidemiology 44 (9): 955-6.

[16] Jackson, A. S., and Polock, M. L. 1978. "Generalized Equations for Predicting Body Density for Men." British Journal of Nutrition 40 (3): 497-504.

[17] Siri, W. E. 1961. "Body Composition from Fluid Spaces and Density: Analysis of Methods." In Techniques for Measuring Body Composition, edited by Brozek, J. and Henschel, A. Washington, DC: National Academy of Sciences, National Research Council.

[18] Otten, J. J., Hellwig, J. P., and Meyers, L. D. 2006. Dietary Reference Intakes: The Essential Guide to Nutrient Requirements. Washington, DC: National Academy Press.

[19] FAO (Food and Agriculture Organization)/WHO (World Health Organization)/UNU (United Nations University) 1991. Energy and Protein Requirement. Report of a Joint
FAO/WHO/UNU expert consultation. World Health Organization. Technical report series, 724.

[20] Ministry of Health. Department of Health Care. Department of Primary Care in 2008.

Food Guide for the Brazilian Population: Promoting Healthy Eating. 1st Ed., 1st reprint. Serie A: Standards and Technical Manuals. Brasilia-DF. (in Portuguese)

[21] Bayios, I. A., Bergeles, N. K., Apostolidis, N. G., Noutsos, K. S., and Koskolou, M. D. 2006. "Anthropometric, Body Composition and Somatotype Differences of Greek Elite Female Basketball, Volleyball and Handball Players." The Journal of Sports Medicine and Physical Fitness 46 (2): 271-80.

[22] Hickey, M. S., Considine, R. V., Israel, R. G., Mahar, T. L., McCammon, M. R., Tyndall, G. L., Houmard, J. A., and Caro, J. F. 1996. "Leptin Is Related to Body Fat Content in Male Distance Runners." American Journal of Physiology 271 (5 Pt 1): E938-40.

[23] Fleck, S. J. 1983. "Body Composition of Elite American Athletes". The American Journal of Sports Medicine 11 (6): 398-403.

[24] Scagliusi, F. B., and Lancha Junior, A. H. 2003. "Underreporting of Energy Intake in Dietary Assessment Methods." Revista de Nutrição 16 (4): 471-81. (in Portuguese)

[25] Krestch, M. J. K., Fong, A. K. H., and Green, M. W. 1999. "Behavioral and Body Sizes Correlates of Energy Intake Underreporting by Obese and Normal-Weight Women." Journal of the American Dietetic Association 99 (3): 300-6.

[26] Edwards, J. E., Lindeman, A. K., Mikesky, A. E., and Stager, J. M. 1993. "Energy Balance in Highly Trained Female Endurance Runners." Medicine and Science in Sports and Exercise 25 (12): 1398-404.

[27] Hill, R. J., and Davies, P. S. 2002. "Energy Intake and Energy Expenditure in Elite Lightweight Female Rowers." Medicine and Science in Sports and Exercise 34 (11): 1823-9.

[28] Fudge, B. W., Westerterp, K. R., Kiplamai, F. K., Onywera, V. O., Boit, M. K., Kayser, B., and Pitsiladis, Y. P. 2006. "Evidence of Negative Energy Balance Using Doubly Labelled Water in Elite Kenyan Endurance Runners prior to Competition." British Journal of Nutrition 95 (1): 59-66.

[29] Krebs-Smith, S. M., Graubard, B. I., Kahle, L. L., Subar, A. F., Cleveland, L. E., and Ballard-Barbash, R. 2000. "Low Energy Reporters vs. Other Reporters: A Comparison of Reported Food Intake." European Journal Clinical Nutrition 54 (4): 281-7.

[30] Goris, A. H. C., Westerterp-Plantenga, M. S., and Westerterp, K. R. 2000. "Undereating and Underrecording of Habitual Food Intake in Obese Men: Selective 
Underreporting of Fat Intake." American Journal of Clinical Nutrition 71 (1): 130-4.

[31] Rumpler, W. V., Kramer, M., Rhodes, D. G., Moshfegh, A. J., and Paul, D. R. 2008. "Identifying Sources of Reporting Error Using Measured Food Intake." European Journal of Clinical Nutrition 62 (4): 544-52.

[32] Burke, L. M., Cox, G. R., Cummings, N. K., and Desbrow, B. 2001. "Guidelines for Daily Carbohydrate Intake: Do Athletes Achieve Them?" Sports Medicine 31 (4): 267-99.

[33] Coyle, E. F. 1992. "Carbohydrate Feeding during Exercise." International Journal of Sports Medicine 13 (Suppl 1): S126-8.
[34] Costill, D. L., and Miller, J. M. 1980. "Nutrition for Endurance Sport: Carbohydrate and Fluid Balance." International Journal of Sports Medicine 1 (1): 2-14.

[35] Nieman, D. C. 2008. "Immunonutrition Support for Athletes." Nutrition Reviews 66 (6): 310-20.

[36] Lemon, P. W. R. 2000. "Beyond the Zone: Protein Needs of Active Individuals." Journal of the American College of Nutrition 19 (5 Suppl): 513S-21S.

[37] Innis, S. M. 2007. "Dietary (n-3) Fatty Acids and Brain Development.” Journal of Nutrition 137 (4): 855-9.

[38] Simopoulos, A. P. 2007. "Omega-3 Fatty Acids and Athletics." Current Sports Medicine Reports 6 (4): 230-6. 